ISAHP 2003, Bali, Indonesia, 7-9 August 2003

\title{
COMPLEX DECISION IN THE ESTABLISHMENT OF ASIAN REGIONAL FINANCIAL ARRANGEMENT
}

\author{
Iwan J Azis \\ Field of Regional Science and Johnson Graduate School of Management \\ Cornell University, Ithaca, NY 14850 \\ ija1@ cornell.edu
}

Keywords: Asian crisis, regional financial arrangement, Analytic Network Process, feedback, supermatrix, IMF, exchange rate stability, BOCR rating.

\begin{abstract}
Summary: The aftermath of the 1997 financial crisis brings about a strong desire among East Asian countries to develop a regional self-help financial networking in order to stabilize the region's financial sector. Some progress towards the creation of a regional financial arrangement (RFA) has been made since the announcement of the Chiang Mai Initiative (CMI) that effectively expanded the swap arrangements to include Japan, the PRC and Korea (hence the term ASEAN+3). However, the results are mixed and skepticism remains. One of the unsettled issues relates to what should be the precise form of RFA that could effectively stabilize the region's financial sector. The focus of this paper is to search for the most suitable form of RFA, the process of which involves a complex decision, having to include not just economic rationales but also political and other considerations. Among the alternative choices, three are explored in the paper: (1) RFA with common currency basket; (2) RFA without a uniformed fixed exchange rate system; and (3) RFA that focuses only on efforts to strengthen the financial system. Measuring consistent prioritization of all benefits, costs, risks, and opportunities of different RFAs are conducted by taking into account the feedback effects between some criteria and alternatives, and between the focus of RFA and the criteria. While a comparison of the results with those obtained from using a simple hierarchy without feedbacks indicate that the resulting weights change, the ranking remains the same. .
\end{abstract}

\section{Introduction}

The 1997 financial crisis prompted the East Asian countries to consider a closer regional financial cooperation and policy coordination. There is a strong desire to develop a regional self-help financial networking. The early proposal initiated by Japan to set up an Asian Monetary Fund (AMF) was shelved because of the rejection of the United States and the IMF.

On May 2000, the existing swap arrangement among ASEAN countries was expanded to include the 3 East Asian countries with mighty economies: Japan, People's Republic of China (PRC) and Korea--hence the term ASEAN+3. The new arrangement, known as the Chiang Mai Initiative (CMI), goes beyond just the expansion of common and bilateral (including repo) swap arrangements. ${ }^{1}$ Focusing on a closer cooperation

\footnotetext{
1 The common swap system known as the ASEAN Swap Arrangement (ASA) is basically designed to provide necessary short-term liquidity mutually among member countries. Under CMI, the ASA membership was expanded to include the 3 East Asian countries, and the total amount of facility derived from members contribution was raised from $\$ 200$ million to $\$ 1$ billion. The Bilateral Swap Arrangement (BSA), on the other hand, is based on a network of bilateral agreements between member countries. The network was expanded under CMI. At the time of this writing, there are already a dozen of such agreements with total size of US\$23.5 billion. This amount excludes the financing through the New Miyazawa Plan (e.g., Japan agreed to swap US\$7.5 billion with Korea and Malaysia in 1999 under the Plan).
} 
and aspiring for a concrete regional financial arrangement, the proposal also stipulates the need for cooperation in regional surveillance and monitoring, particularly of capital flows. ${ }^{2}$

The main question for the East Asian policy makers is, what kind of cooperation the region needs? More particularly, what form of Regional Financial Arrangement (RFA) is most suitable for achieving the stability of financial sector and minimizing the volatility of the exchange rate, given the benefits and opportunities that may arise and costs and risks that have to be faced when such RFA is selected? This issue essentially involves a complex decision, having to include not just economic rationales but also political and other considerations.

This paper shows that the quality of the choice can be significantly enhanced by applying the Analytic Network Process (ANP), taking into account the benefits, opportunities, costs, and risks of the selected RFA. Some important factors to consider are first discussed in the next Section.

\section{Important Factors To Consider}

The 1997 crisis has caught many by surprise, much more severe and contagious than expected. In addition to designing swap arrangements, in anticipating future crises a better surveillance and monitoring system is therefore required. So is a more effective policy response. Consequently, crisis prevention and crisis management should be the focus of any new proposals. In the model, this is captured in a cluster that contains the following nodes: Crisis Prevention and Crisis Management (Figure 1).

Intensive discussions following CMI brought about debates over the ultimate objectives and the precise form of regional financial arrangement. The three major objectives of establishing RFA considered in this study are: (1) to minimize the exchange rate volatility, labeled $\boldsymbol{E} \boldsymbol{R}$ Stability; (2) to strengthen the region's financial sector and securities market, labeled Strengthening Financial Sector; and (3) to avoid financial contagion (Avoid Contagion) that could destabilize even the fundamentally strong economies in the region.

\section{Alternative Forms of RFA}

One of the proposed ideas regarding the exchange rate system is to implement a Common Currency Area (CCA) based on a certain basket that may lead to a Currency Union (CU). The argument supporting this idea rests upon a fundamental reason i.e., in order to stimulate trade, that exchange rate stability is essential. In fact, some currencies in the region have already been de facto following a basket system.

In its critical report, the Tokyo-based Asian Development Bank Institute (ADBI) argued that an intermediate exchange rate system would be most suitable for post-crisis Asia. Freely floating exchange rate and currency board (hard peg) regimes are not appropriate. Although potentially it can help to limit capital inflows, a floating system has two potential problems: volatility in the short run and misalignment in the medium run. ${ }^{3}$ A currency boards system, on the other hand, is typically used in economies where the public has lost confidence in domestic monetary and exchange rate policy due to bouts of hyperinflation, requiring that a fixed exchange rate serve as a new anchor for monetary policy. This is clearly not the case in the Asian countries.

2 Combined all together, interestingly these elements constitute something not far different from the originally proposed AMF.

3 Since Asian economies tend to have narrow and shallow capital markets, they are highly vulnerable to exchange rate volatility, including manipulations by a few large players in the international capital market. Bandwagon or herding effects can easily magnify such volatility. A currency appreciation following capital inflows can induce even greater capital inflows, further appreciating the currency and resulting in a medium-term misalignment. The exchange rates can thus lose touch with fundamentals for an extended period of time, seriously distorting domestic resource allocation between tradables and non-tradables. 
With relatively open capital accounts, Asian countries can adopt a managed float exchange rate policy that would be consistent with its sustainable competitiveness. When based on an appropriately trade-weighted currency basket rather than a single currency, adjusted appropriately for differences in international inflation rates, the exchange rate system could help facilitate trade, FDI and economic growth, and accommodate pressures from too abrupt and large swings in capital flows. The basket should include major currencies, such as the US dollar, the yen, and the euro, as well as others representing major trading partners of the economy concerned. The degree of flexibility could vary from economy to economy depending on differences in the magnitude of capital flows and the development of resilient capital markets. In Figures 1 to 4, the form of RFA with this exchange rate system is labeled $\boldsymbol{R F A - C o m m E R}$.

It is important to note, however, that the proposed managed float system is to be part of an integrated policy package, not a stand alone policy. For example, governments should maintain a level of foreign reserves that exceeds the amount of its outstanding external short-term debt.

Meanwhile, there is another floated proposal that is less strict, i.e., not requiring a uniformed fixed exchange rate system although it still focuses on exchange rate stabilization. Proponents of this proposal argued that there is no reason why a floating system cannot be consistent with increased regional integration. The case of market integration in North America demonstrates that it can (e.g., Mexico's relative success in integrating with the US market without fixing the exchange rate). In this study, the form of RFA without common currency is labeled $R F A-N o C o m m E R$.

While there is a fundamental difference between the above two forms, both require the same necessary condition, i.e., a stable and efficient financial system. It is in this connection another proposed scenario is simply to create a regional cooperation that focuses only on efforts to strengthen the financial system by neither specifying a particular exchange rate regime nor targeting exchange rate stability. This is labeled $\boldsymbol{R F A - N o E R}$. More specifically, this scenario suggests the creation of some kind of Regional Financial Institution (RFI) in the following areas: (1) technical assistance to strengthen prudential supervision and regulation; (2) training programs for bank inspectors, securities and exchange commissioners; (3) management of reserve, clearing and settlement services to member central banks; and (4) regional agreements on capital, liquidity standards, and regulatory processes to promote the stability of banking systems, and on standards for information disclosure, securities listing, and corporate governance for the development of regional financial markets (Eichengreen, 2003). Unlike the other two forms of RFA, the proposed RFI essentially stays away from the attempt to stabilize asset prices and the exchange rate. It is argued that the two should be left to the markets.

\section{Benefit Criteria for Selecting RFA}

A real fundamental question in the search for RFA is: why does the region need another arrangement, especially given the fact that the IMF has been functioning as a lender of last resort through its Supplementary Reserve Facility (SRF) and Contingent Credit Line (CCL)? This is precisely the issue raised by those opposing the AMF concept in $1998{ }^{4}$

Can't the stated objectives be acquired by making necessary adjustments to the existing global institutions (e.g., the IMF)? Even if a new institution is justified, why should it be regional, not global, in its focus?

Improvements can probably be made within the existing framework and institution without creating a new arrangement. But the severity of a capital account crisis like in 1997 requires a fast disbursement of a large amount of liquidity. This put serious constraints on the IMF to act in a timely manner with sufficient financial resources. Then there is also inappropriateness of IMF-recommended policies. While the event in 1997 was categorically a capital account crisis, the policies suggested by the IMF were those more

4 Unlike the reaction towards AMF, a senior official from the U.S Treasury who attended the meeting in Chiang Mai indicated that unofficially Washington supports the CMI although it had to wait for further development before an official reaction can be made. A few weeks after the CMI was announced, IMF's Horst Kohler was also positive towards the idea although he stressed on the complementary nature of CMI to the IMF program (IMF News Brief No. 00/36, June 2, 2000). 
appropriate for a current account crisis. ${ }^{5}$ The IMF's global mandate is to provide financial assistance at any time to many member countries, not specifically to countries in a particular region. From this perspective, Regional-Focus and Quick Disbursement are among the benefit criteria (see Figure 1). ${ }^{6}$

The merit of a regional-oriented cooperation was evident from the far too small supplementary support to the IMF program in Thailand and Indonesia in 1997/98 when such cooperation did not exists. Furthermore, none of the supplementary support during the time come from outside the region. ${ }^{7}$

Figure 1. Network of Benefits Cluster

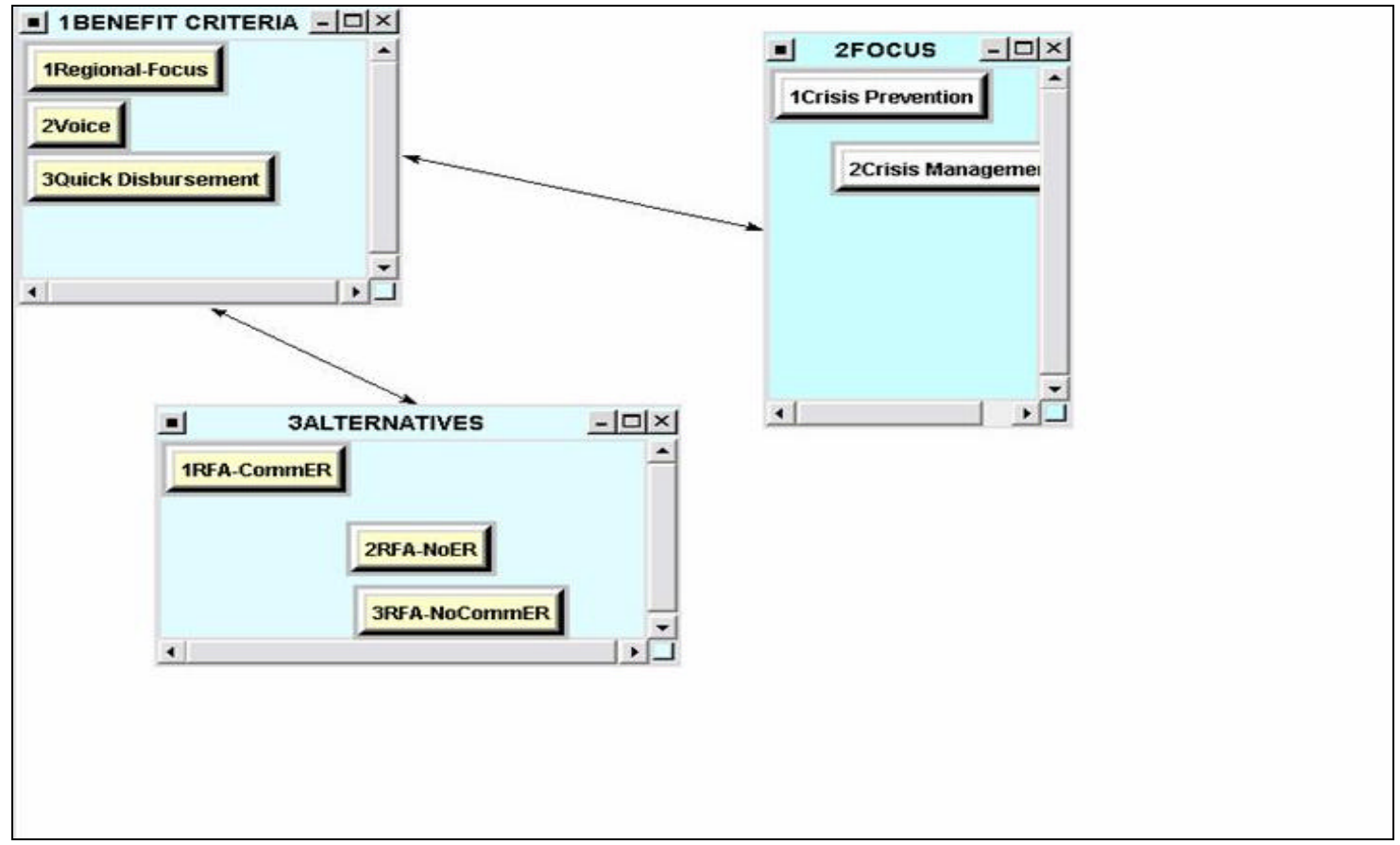

In a looming speculative attack, fast and area-focused actions are critically needed to stabilize the currency. Exchange rate volatility will not only hurt trade and reduce investment in the region, but it could also cause two related problems. (1) Higher exchange risks (with limited hedging possibilities), leading towards higher interest rates that can undermine economic growth, and (2) Discouraging the development of capital markets because residents face constant fluctuation in the real value of domestic assets due to exchange rate volatility. This may encourage residents to invest in more stable and liquid financial instruments abroad.

Another formidable argument favoring a regional-focus arrangement is common to many international issues, i.e., dis-proportionally weak voting rights of less developed countries. Individually, Asian countries have limited quotas and voting rights in the IMF. For East Asia in particular, they do not appropriately reflect the region's economic power. An arrangement with regional-focus would certainly help raise the

5 In some cases, policies imposed by the IMF did not result in intended outcomes, as was the case at the early stage of the crisis; see Azis (forthcoming) and Azis (2002).

6 To facilitate quick disbursement without the risk of moral hazard, soft conditionalities, and low repayment capacity, a system of prequalification is needed (ADBI, 2003).

${ }^{7}$ It should not be surprising that at one point Thailand along with Malaysia opposed the idea of linking CMI with the IMF program. It was eventually agreed that only if further studies done by a designated study group recommend otherwise, the link can be gradually cut off. 
weight of the region's voice in the international community. In Figure 1, the benefit from raising the region's voice is labeled Voice.

\section{Opportunities Arising From RFA}

A new RFA can provide a set of opportunities the region can take advantage from. The event in 1997 had clearly shown that the pre-crisis macroeconomic fundamentals of the crisis countries were not weak. The fragility was mainly in the financial sector. Unlike the IMF's mandate in overseeing all macroeconomic issues, the new arrangement is expected to concentrate only on financial issues. ${ }^{8}$ Problems in the financial sector are complex that they need to be addressed separately, not to be besieged by other macroeconomic issues. Hence, Financial-Focus is designated as one of the nodes within the opportunities cluster in Figure 2. The financial-oriented nature of the regional arrangement provides opportunities for member countries to coordinate and cooperate in this sector.

Figure 2. Network of Opportunities Cluster

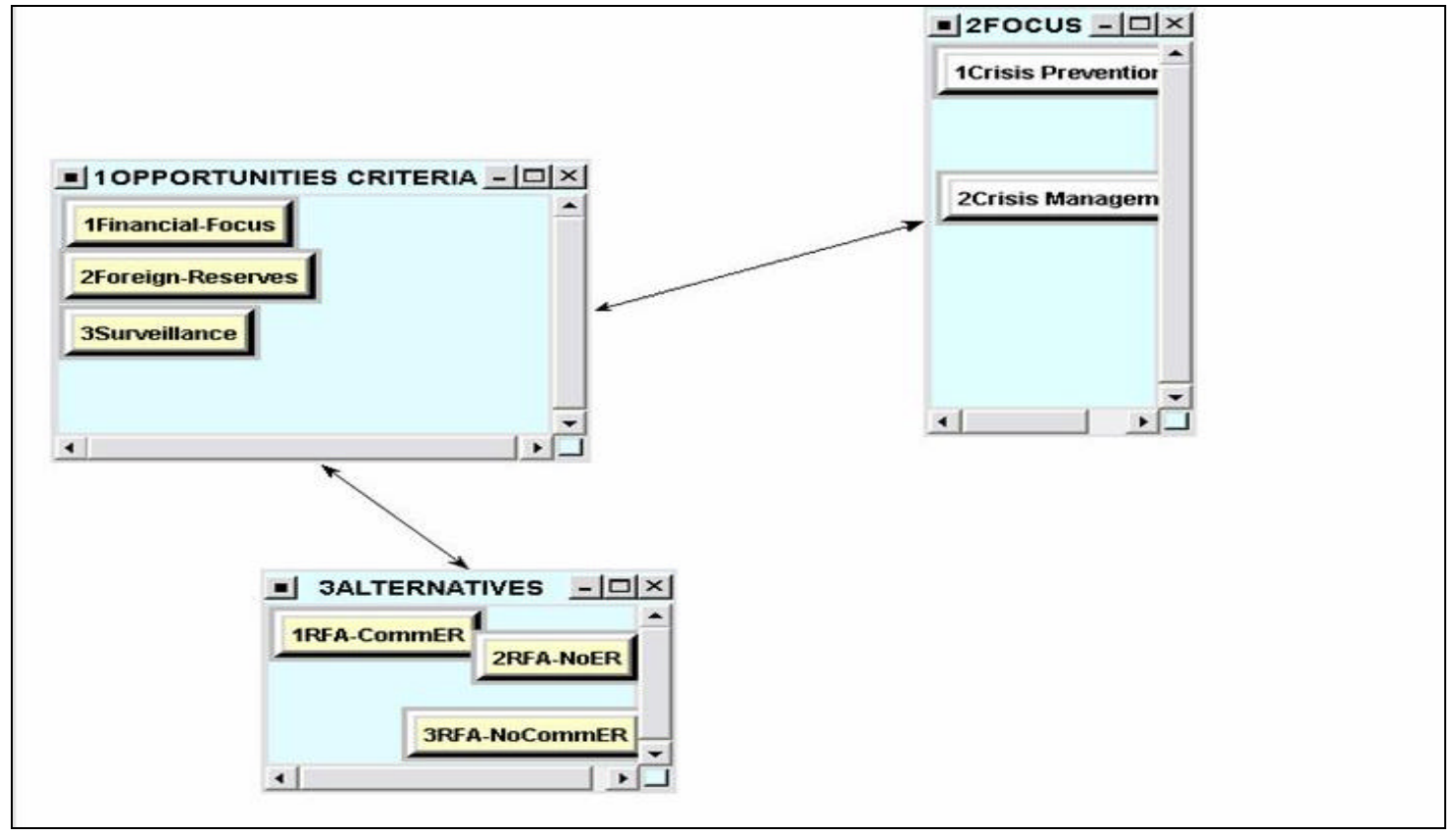

By focusing on financial matters alone, the range of policy response is also widened. One such a policy response is capital control. While the debate over the effectiveness of capital control continues (e.g., Malaysian style or a-la Chilean model), many acknowledge the benefits of imposing such controls. The Malaysian example shows that selective and temporary controls could help contain the crisis better. At the very least it provided a breathing space that would have not been possible without controls. Restricting non-residents' holding of domestic assets can also reduce the frequency and intensity of currency speculation, diminishing the probability of further contagion.

${ }^{8}$ Commenting on this issue, the Director of the IMF Institute, Mohsin Khan, suggested that IMF was illequipped to combat the new type of crisis like the one in Asia. He remarked: "A lot is related to financial sector issues, where the IMF staff did not have necessary expertise at all....we find ourselves making standard policy prescriptions....very seldom would you go wrong if you said 'raise interest rates and tighten fiscal policy'....I thought the teams in Asia were sort of conditioned by the framework they had in mind." (see Blustein, 2001). 
Another example of policy response that would have been impossible to implement under a normal IMF program is to make private creditors get involved with crisis resolution. ${ }^{9}$ If the private sector simply walks away, the shortage of international liquidity will seriously worsen and a larger amount of international assistance will be required. This is the reason why there is now great interest among multilateral agencies including the IMF to involve private-investor/creditors.

Another important opportunity from having a form of RFA is to conduct a more effective surveillance mechanism and to monitor the development of the region's financial sector (e.g., monitoring capital flows). Hence, a node labeled Surveillance is added into the opportunities cluster in Figure 2. This is not only necessary for crisis prevention but it also fits aptly with the conditionalities that must be imposed when some members need to get hold of financial resources through the swap mechanism under the new arrangement.

The current ASEAN+3 surveillance process is inadequate. It specifies neither the precise content of the information nor the minimum information to be exchanged among member countries. A credible surveillance report should address emerging problems and effectively signal any potential risks early enough to allow policy makers to respond. It should also indicate the repercussions on social conditions such as income distribution, poverty etc, and goes beyond just repeating the assessments made by other international organizations (the IMF, the World Bank and the Asian Development Bank). A standard report that simply warehouses information is not helpful. If fact-finding missions are deemed unacceptable, either because of the costs associated with a large bureaucracy or because of the political sensitivity about foreign intrusion, then a common template ought to be used (Azis \& Woo, 2003; Wang \& Woo, 2002, ADB-I, 2003).

Having RFA also enables member countries to utilize the foreign reserves in a more productive way. This is represented by a node labeled Foreign Reserves in the opportunities cluster. It is a basic rule for governments to maintain a level of foreign reserves that exceeds the amount of its outstanding external short-term debt. But excessive accumulation of foreign reserves is a waste of valuable financial resources, involving high opportunity costs (i.e., low US Treasury bonds' interest rate compared with high rate of return to domestic capital). Through resource pooling, RFA could considerably reduce such a waste of resources.

\section{Costs Criteria}

There are difficulties in establishing RFA. The first and perhaps most immediate one is the Complex Bureaucracy (see Figure 3). This is often the case when a new institution is established. The problem can be aggravated by the fact that the region is fairly heterogeneous, having some degrees of suspicion among its members. As the experience of other regional cooperation has suggested, the problem of bureaucracy will be manifested through Difficult Coordination among member countries. Unless a clear and concrete cooperative mechanism is laid out, there will certainly be a serious coordination adjustment problem.

A more concrete plan related to the financial arrangement is supposed to be established in the next meeting scheduled to take place on May 2004. Badly needed is the specified target on both the item and the deadline for achievement (labeled Target Specification in Figure 3). It is very difficult for the new arrangement to be credible if no specific targets are set. Unfortunately, the region--particularly ASEAN countries--do not have exemplary points in this regard. The principle of non-interference (should the target is not met) may deter the need to make the target specific. The recovery process, albeit varied between countries, and greater interest towards regional trade rather than financial arrangement, may have some influences on this matter as well. Uncertainties and fears of failure can also prevent member countries to come forward with certain targets. Last but certainly not least, the so-called "Asian values" glorifying consensus and informality stand in contrast with an explicit target setting.

${ }^{9}$ One approach is to require private creditors to roll over the maturing claims, which effectively suspends payments and compels private creditors to negotiate, such as what they did with Korean debts in December 1997.

Proceedings $-7^{\text {th }}$ ISAHP2003 Bali, Indonesia 
Figure 3. Network of Costs Cluster

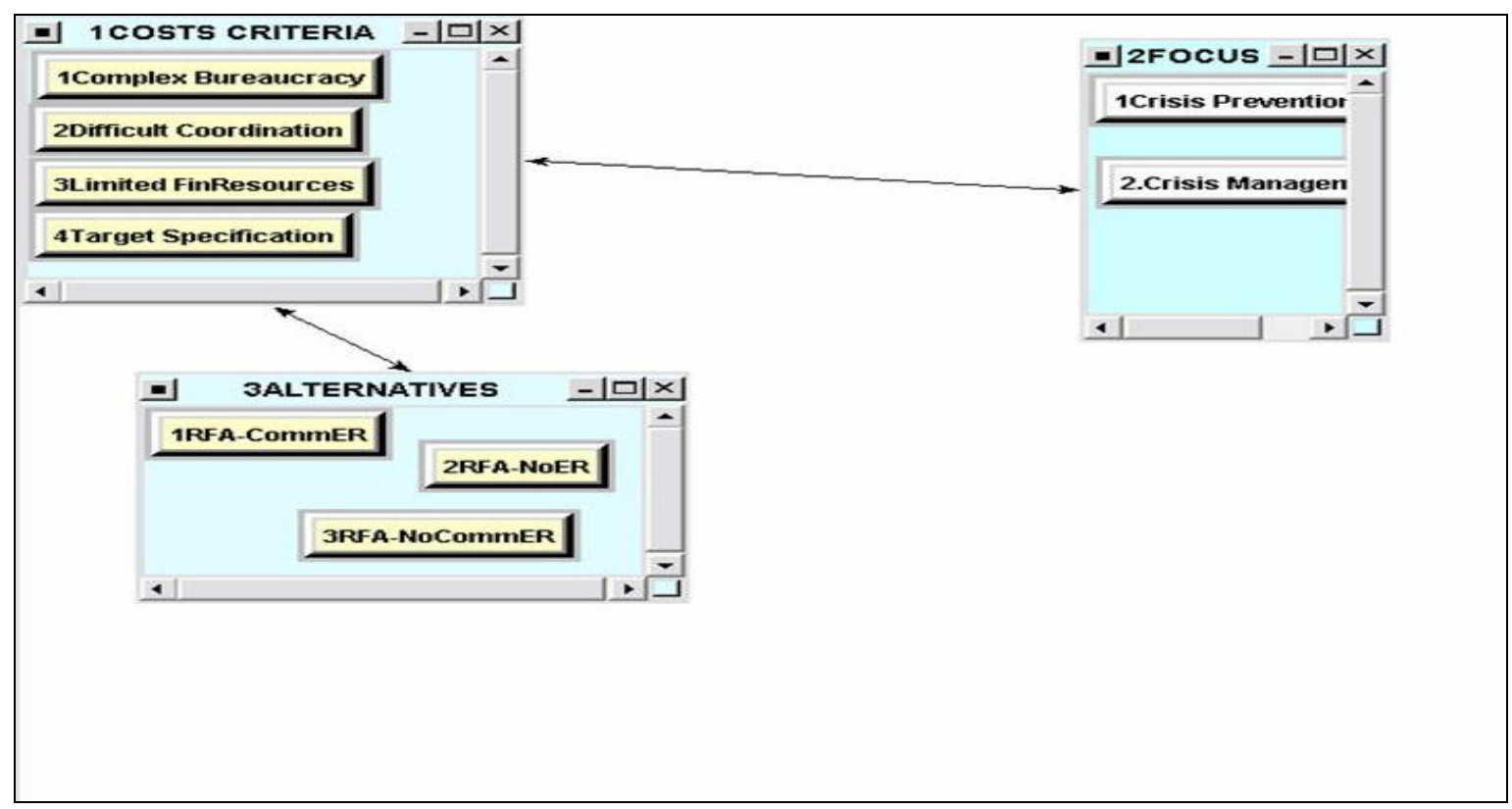

All the above "costs" can seriously undermine the efforts to meet the original goals of a regional financial arrangement. But perhaps the most important cost that could forestall the process is the large amount of financial resources required to make the arrangement credible and taken seriously by the financial market. This is labeled Limited FinResources in the costs cluster. While Japan may be more willing to commit a greater amount of resources, the PRC would not necessarily support such a move since it could jeopardize its desire to become a new major player in the region. Other member countries such as Singapore and Brunei may be reluctant to increase the committed amount since they are aware of their position being more of a swap provider than direct beneficiaries in the arrangement.

It has been indeed very difficult to raise the amount of the swap facility. Even if commitments among the swap providing countries are strengthened, effectively raise the upper limit of liquidity available, objections from the IMF remain a serious obstacle. The current Bilateral Swap Arrangement (BSA) only allows an immediate disbursement of up to 10 percent of the maximum amount, providing the swap providing countries can agree. Above that amount, the swap requesting countries are required to accept the IMF program.

\section{$\underline{\text { 5. Risks Criteria }}$}

Different forms of RFA pose different risks. One of the serious risks is the potential conflict that may arise due to the fact that some governments have to abide with the existing arrangements they made with other international organizations including the IMF. The RFA may contain some features not in line with those arrangements. Capital controls and bail-in program discussed earlier are the noted examples. Given the gap in financial technology, the limited number of expertise, and the asymmetry in market influence, the aforementioned conflict is difficult to overcome. The results may be a worsening problem of coordination particularly in making the features of RFA consistent with those of other arrangements. This risk is labeled DomCoordination in Figure 4.

There are also risks of failures caused by a deep suspicion among member countries. This may be due to the Heterogeneity of the region. Another risk is related to a lack of concrete political integration (labeled Political in the risks cluster). As long as there is no willingness to pool political sovereignty to make room for the creation of regional institution with real power, any meaningful and effective RFA would not be 
feasible. The absence of clear regional leadership and consensus (e.g., due to Japan's feeble economy) is likely to worsen the situation.

\section{Figure 4. Network of Risks Cluster}

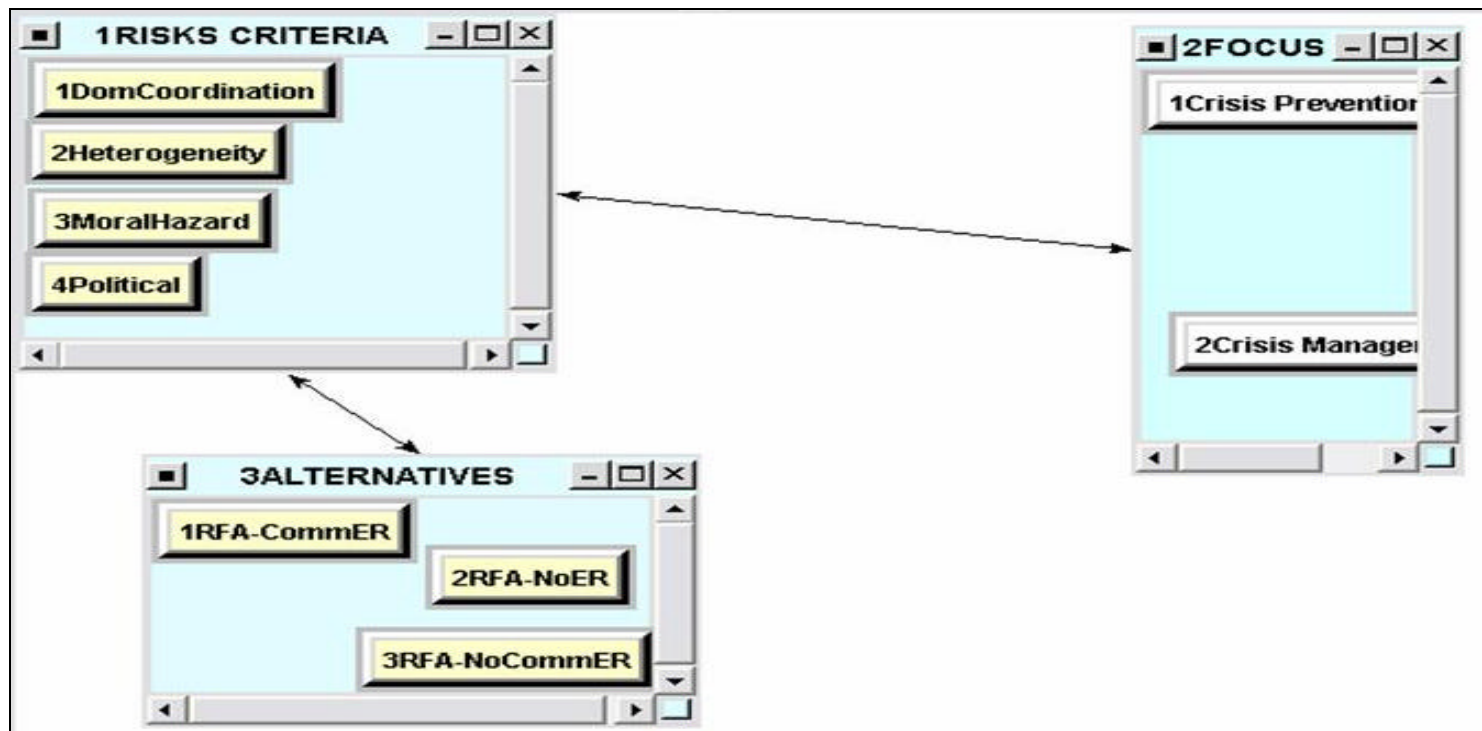

Still another important risk is serious Moral Hazard. The problem of moral hazard is not only related to the behavior of borrowers (swap recipients), but also to the questionable representation of government officials in power whose interest may be inconsistent with broader interests of the citizens of the country concerned. This classical "principal/agent problem" could be severe when citizens do not fully understand or appreciate the consequences of decisions on complex issues--such as financial matters--made in their name (Mussa, 2002). There is also a possible risk of financial support not being repaid. The moral hazard issue in this respect could be related to a situation whereby the financial support was given and used for reasons other than the agreed criteria. There is no question that moral hazard problems pose a serious risk. On the other hand, it is unclear whether RFA's moral hazard would be any more severe than that implied in the context of the IMF program. What it suggests is that, the formulation and enforcement of conditionalities must be a critical part of the swap arrangement when such facilities need to be activated.

A complete list of factors (clusters and nodes) discussed above is shown in the Appendix. In the next Section, it is shown how the complex decision involving all those factors can be made.

\section{Searching for Most Suitable Form of RFA}

By applying the ANP, a set of consistent prioritization is generated for all the benefits, opportunities, costs, and risks (BOCR) of the three forms of RFA discussed earlier. Figure 5 displays the basic model framework. 
Figure 5. Basic Model Framework

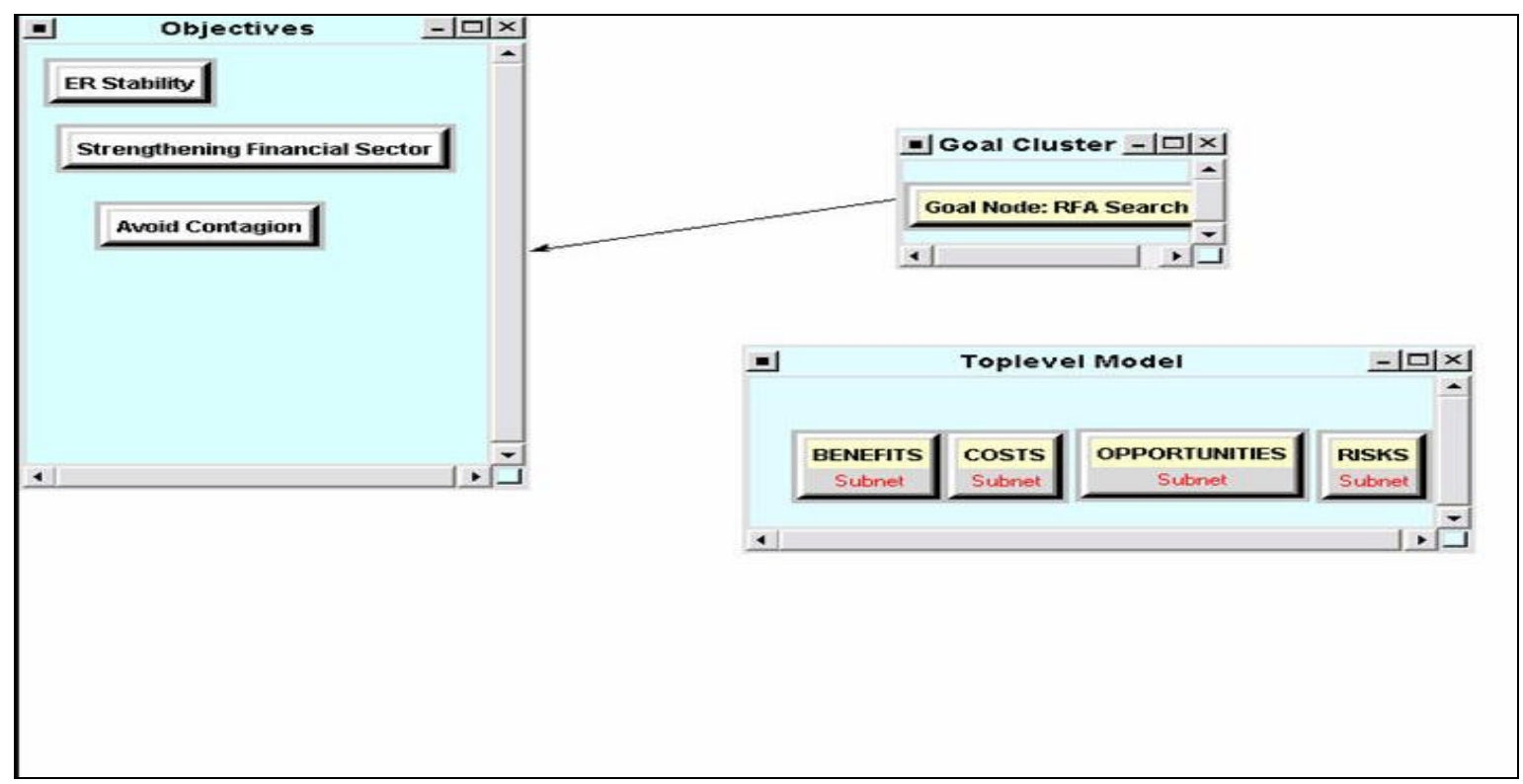

Pairwise comparisons are first made on the three major objectives of establishing RFA. ${ }^{10}$ The resulting priority ranking is: Strengthening Financial Sector (.7223), ER Stability (.2050), and Avoid Contagion (.0727). Clearly, the most important goal of all the efforts to establish RFA is to strengthen the region's financial sector.

There are three clusters in each of BOCR: focus cluster, criteria cluster, and alternatives cluster (see again Figures 1 to 4). The nodes inside the criteria cluster and those within the focus cluster are interdependent. Consequently, a typical set of questions for the benefit criteria would be:

1. Which benefit most likely to emerge when the purpose of creating RFA is to prevent a crisis (Crisis Prevention)?

2. The feedback question: For which purpose (Crisis Management or Crisis Prevention) will a benefit criterion, say, exchange rate stability (ER Stability) be most useful to have?

A similar set of questions are used for the opportunities, costs, and risks (Figures 1 to 4 ). Note that all arrows point in two opposite directions, indicating the presence of feedbacks.

In comparing the alternative forms of RFA with respect to each of the criteria, there is also a feedback effect. For an illustration, a typical set of questions for, say, the costs criteria would be:

1. Given a particular difficulty (e.g., in making Target Specification), which form of RFA is the most costly to have?

2. The feedback question: What kind of difficulty to be faced if a certain form of RFA, say, RFANoER, is selected?

Combining the prioritization results from linking the three clusters yield the relevant supermatrix (weighted and unweighted), based upon which the limiting supermatrix is derived (Tables 1 to 4 ).

${ }^{10}$ Results of the comparisons are generated by using Super Decision software. The author received a helpful guidance from Rozann W. Saaty in using the software, for which he wishes to thank her deeply. Similar comparisons can actually be made by following a series of step to generate the approximated eigen vector of the relevant matrix (see Azis \& Isard, 1996). 
Table 1. Limiting Supermatrix for Benefit Cluster

\begin{tabular}{|c|c|c|c|c|c|c|c|c|}
\hline & 1Regional-Focus & 2Voice & 3Quick Disbursement & 1Crisis Prevention & 2Crisis Management & 1RFA-CommER & 2RFA-NOER & 3RFA-NoCommER \\
\hline Regional-Focus & 0.20201 & 0.202 & 0.20201 & 0.20201 & 0.20201 & 0.20201 & 0.20201 & 0.20201 \\
\hline Vooce & 0.05524 & 0.055 & 0.05524 & 0.05524 & 0.05524 & 0.05524 & 0.05524 & 0.05524 \\
\hline 3Quick Disbursement & 0.24275 & 0.243 & 0.24275 & 0.24275 & 0.24275 & 0.24275 & 0.24275 & 0.24275 \\
\hline 1Crisis Prevention & 0.07244 & 0.072 & 0.07244 & 0.07244 & 0.07244 & 0.07244 & 0.07244 & 0.07244 \\
\hline 2Crisis Management & 0.17755 & 0.178 & 0.17755 & 0.17755 & 0.17755 & 0.17755 & 0.17755 & 0.17755 \\
\hline RFFA-CommER & 0.11268 & 0.113 & 0.11268 & 0.11268 & 0.11268 & 0.11268 & 0.11268 & 0.11268 \\
\hline 2RFA-NoER & 0.02633 & 0.026 & 0.02633 & 0.02633 & 0.02633 & 0.02633 & 0.02633 & 0.02633 \\
\hline 3RFA-NoCommER & 0.11099 & 0.111 & 0.11099 & 0.11099 & 0.11099 & 0.11099 & 0.11099 & 0.11099 \\
\hline
\end{tabular}

Table 2. Limiting Supermatrix for Costs Cluster

\begin{tabular}{|c|c|c|c|c|c|c|c|c|c|}
\hline & 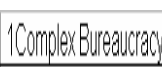 & 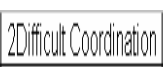 & 3 limited FinResources: & ATarod Spectication & Coisis Prevertion & | 2Crisis Maracementit. & |PFA-Cormb & REFANAER & SPFA-NOCOOMnEF \\
\hline Comple Bureacricac & 005139 & 005139 & 0.05139 & 005139 & 005139 & 005139 & 0.56130 & 0.05139 & 005139 \\
\hline QificcultCoondination & 0.06841 & 0.00641 & 0.08841 & 0.08604 & 0.00841 & 0.08604 & 008641 & 0.00641 & 0008041 \\
\hline 3 Linited FinResources & 0.9002 & 0.2002 & 02002 & 0.2902 & 0.2002 & 0.902 & 0.902 & 0.2902 & 0.2902 \\
\hline 4TargetSpecilication & 0.772 & 0.072 & 0.072 & 0.072 & 0.072 & 0.772 & 0072 & 0.072 & 0.072 \\
\hline CCisis Prevertion & 0.0539 & 0.0539 & 00639 & 00539 & 006390 & 015390 & 0.0539 & 0.0539 & 0.0539 \\
\hline 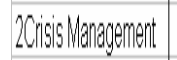 & 01961 & 01961 & 01081 & 019961 & 01961 & 01961 & 019661 & 019601 & 01961 \\
\hline 1FFA-CommER & 0.18001 & 0.10001 & 0.16001 & 0.16001 & 0.10001 & 0.18001 & 0.6001 & 0.16001 & 0.10001 \\
\hline REFANNER & 0.06998 & 0,06098 & 0.02898 & 0.02698 & 0.06998 & 0.06698 & 000698 & 002608 & 0,02098 \\
\hline SFFA-NCOCOMER & 0060301 & 006001 & 000801 & 0.06301 & 0.06201 & 0.06301 & 0.66301 & 0.06301 & 0.06301 \\
\hline
\end{tabular}

Table 3. Limiting Supermatrix for Opportunities Cluster

\begin{tabular}{|c|c|c|c|c|c|c|c|c|}
\hline & TFinancial-Focus & ZForeign Resenves & 3Sunvellance & 1Crisis Prevention & ZCrisis Management: & 1RFA-CommER & 2RFA-NOER & 3RFA-NOCOmmER \\
\hline Financial-Focus & 0.15999 & 0.15999 & 0.15999 & 0.15999 & 0.15999 & 0.15999 & 0.15999 & 0.15999 \\
\hline IForeign Resenves & 0.19698 & 0.19698 & 0.19698 & 0.19698 & 0.19698 & 0.19698 & 0.19698 & 0.19698 \\
\hline 3survellance & 0.14303 & 0.14303 & 0.14303 & 0.14303 & 0.14303 & 0.14303 & 0.1430 .3 & 0.143013 \\
\hline 1Crisis Prevertion & 0.12422 & 0.12422 & 0.12422 & 0.12422 & 0.12422 & 0.12422 & 0.12422 & 0.12422 \\
\hline 2Crisis Mannagement. & 0.12579 & 0.12579 & 0.12579 & 0.12579 & 0.12579 & 0.12579 & 0.12579 & 0.12579 \\
\hline 1RFA-CommER & 0.10646 & 0.10646 & 0.10646 & 0.10646 & 0.10640 & 0.10640 & 0.10646 & 0.10646 \\
\hline RREA.NOER & 0.03767 & 0.03767 & 0.03767 & 0.03767 & 0.03767 & 0.03767 & 0.03767 & 0.03767 \\
\hline 3RFA-NOCOMmER & 0.10587 & 0.10587 & 0.10587 & 0.0587 & 0.10587 & 0.10587 & 0.10587 & 0.10587 \\
\hline
\end{tabular}


Table 4. Limiting Supermatrix for Risks Cluster

\begin{tabular}{|c|c|c|c|c|c|c|c|c|c|}
\hline & 1DomCoordination & ZHeterogenenily & Moral Hazard & $\mid$ | PPolitical| 1 & 1Crisis Prevention & ZCrisis Management. & 1RFA.CommER & 2RFA-NOER & 3RFA-HOCOMmER \\
\hline 1DomCoordination & 0.13273 & 0.13273 & 0.13273 & 0.13273 & 0.13273 & 0.13273 & 0.13273 & 0.13273 & 0.13273 \\
\hline 2Heterogenenily & 0.06831 & 0.06831 & 0.06831 & 0.06831 & 0.06831 & 0.06831 & 0.06831 & 0.06831 & 0.06831 \\
\hline 3Moral Hazard & 0.17517 & 0.17517 & 0.17517 & 0.17517 & 0.17517 & 0.17517 & 0.17517 & 0.17517 & 0.17517 \\
\hline APolitical & 0.12379 & 0.12379 & 0.12379 & 0.12379 & 0.12379 & 0.12379 & 0.12379 & 0.12379 & 0.12379 \\
\hline ICrisis Prevention & 0.11946 & 0.11946 & 0.11946 & 0.11946 & 0.11946 & 0.11946 & 0.11946 & 0.11946 & 0.11946 \\
\hline 2Crisis Management & 0.13054 & 0.13054 & 0.13054 & 0.13054 & 0.13054 & 0.13054 & 0.13054 & 0.13054 & 0.13054 \\
\hline 1RFA.CommER & 0.15778 & 0.15778 & 0.15778 & 0.15778 & 0.15778 & 0.15778 & 0.15778 & 0.15778 & 0.15778 \\
\hline 2RFA-NOER & 0.02929 & 0.02929 & 0.02929 & 0.02929 & 0.02929 & 0.02929 & 0.02929 & 0.02929 & 0.02929 \\
\hline 3RFA-NoCommER & 0.06294 & 0.06294 & 0.06294 & 0.06294 & 0.06294 & 0.06294 & 0.06294 & 0.06294 & 0.06294 \\
\hline
\end{tabular}

The next step is to conduct the ratings for BOCR. This step is necessary because in real world the importance of each of the BOCR components is often weighted differently (Saaty, 1996). In some cases, the benefits and opportunities are assigned higher rating than the costs and risks. In other cases the opposite may be the case. If this step is skipped, implying that all components of the BOCR are assumed to have the same weights, the overall results show that RFA without a common currency basket but aiming at exchange rate stability (RFA-NoCommER) is the most suitable form of RFA, receiving highest weight of .4295 . The weights for RFA-NoER and RFA-CommER are .3010 and .2695 , respectively:

Table 5. Synthesis Under Equal BOCR Ratings

\begin{tabular}{|l|l|l|l|l|l|}
\hline Graphic & Alternatives & Total & Normal & Ideal & Ranking \\
\hline & 1RFA-CommER & 0.5000 & 0.2695 & 0.6276 & 3 \\
\hline & 2RFA-NoER & 0.5583 & 0.3010 & 0.7008 & 2 \\
\hline & 3RFA-NoCommER & 0.7967 & 0.4295 & 1.0000 & 1 \\
\hline
\end{tabular}

However, considering the trend since the announcement of the CMI, and the recent development in the financial sector reform throughout the region, a more likely rating for BOCR is as follows:

Table 6. Most Likely BOCR Ratings

\begin{tabular}{|l|l|l|l|l|l|l|}
\hline Graphic & Ratings Alternatives & Total & Ideal & Normal & Ranking \\
\hline & BENEFITS & 0.9525 & 1.0000 & 0.2870 & 2 \\
\hline & COSTS & 0.4612 & 0.4842 & 0.1390 & 4 \\
\hline \hline & OPPORTUNITIES & 0.9525 & 1.0000 & 0.2870 & 3 \\
\hline & RISKS & 0.9525 & 1.0000 & 0.2870 & 1 \\
\hline
\end{tabular}

Note that while the benefits and opportunities are rated high, the risks also receive an equally high rating. The heterogeneity among member countries, including in the speed and coverage of the post-crisis financial reform, elevates the importance of the risk factor. Notably, the risk of creating more suspicions regarding the repayment capacity of swap receiving countries on the one hand and the enforcement of conditionalities on the other, remains high.

With the above BOCR rating, the resulting priority of RFA is as follows: 
Table 7. Synthesis Under Most Likely BOCR Ratings

\begin{tabular}{|l|l|l|l|l|l|l|}
\hline Graphic & Alternatives & Total & Normal & Ideal & Ranking \\
\hline & 1RFA-CommER & 0.5740 & 0.2995 & 0.6958 & 2 \\
\hline & 2RFA-NoER & 0.5179 & 0.2702 & 0.6278 & 3 \\
\hline & 3RFA-NoCommER & 0.8249 & 0.4304 & 1.0000 & 1 \\
\hline
\end{tabular}

Clearly, the dominance of RFA-NoCommER continues. However, unlike in the preceding case, RFA with common currency based on a basket system is now ranked higher than RFA without specifying exchange rate target and exchange rate regime. The relatively low rating for costs criteria implies that difficulties in coordination, in pooling a large amount of financial resources, in target specification, and in overcoming the bureaucracy when a common currency is adopted, are not of significant factors.

This is supported by the results of a sensitivity analysis. When these costs (along with the risks) criteria are rated higher than the benefits and opportunities, the priority ranking of RFA changes significantly.

Table 8. Synthesis Under Low BO and High CR Ratings

\begin{tabular}{|l|l|l|l|l|l|}
\hline Graphic & Alternatives & Total & Normal & Ideal & Ranking \\
\hline \hline & 1RFA-CommER & 0.0742 & 0.0498 & 0.0947 & 3 \\
\hline \hline & 2RFA-NoER & 0.7836 & 0.5259 & 1.0000 & 1 \\
\hline & 3RFA-NoCommER & 0.6323 & 0.4243 & 0.8069 & 2 \\
\hline
\end{tabular}

\section{Conclusions}

Some progress has been made since the Chiang Mai Initiative (CMI) was announced. But the results are mixed and skepticism remains. One of the unsettled issues relates to the precise form of RFA that could effectively stabilize the region's financial sector. Yet, at this stage of development, a more concrete form must already be specified. Among the alternative forms, three are explored in this study: (1) RFA with common currency basket; (2) RFA without a uniformed fixed exchange rate system; and (3) RFA that focuses only on efforts to strengthen the financial system by neither specifying a particular exchange rate regime nor targeting exchange rate stability.

Selecting the most suitable form is a complex decision, having to include not just economic rationales but also political and other considerations. Arguments for creating an alternative regional arrangement have been elaborated, covering all factors (clusters and nodes) that need to be considered. Attempts are subsequently made to come up with the most suitable format of RFA by applying the Analytic Network Process (ANP). A consistent prioritization for all networks in the clusters --for benefits, opportunities, costs, and risks--is done by taking into account the feedback effects between clusters.

In the process, ratings for BOCR are made: first, having equal rating; second, using the most likely rating; and third, using lower rating for the benefits and opportunities than for costs and risks. The results show that under the equal rating of BOCR a regional arrangement without a common currency basket aiming at exchange rate stability $(R F A-N o C o m m E R)$ is the most suitable form for the region.

When the most likely ratings of BOCR is applied, the dominance of RFA-NoCommER remains, but the relative preference of the other two forms is reversed. Unlike in the equal rating case, RFA with common currency based on a basket system (RFA-CommER) is now ranked higher than RFA without specifying exchange rate target and exchange rate regime (RFA-NoER). This implies that difficulties in coordination and in pooling a large amount of swap facility, as well as in target specification and overcoming the 
bureaucracy when a common currency is adopted are not likely to be too prohibitive. This is consistent with the results of a sensitivity analysis that show when these costs criteria are rated higher a common currency is the least suitable form of RFA. Under such circumstances, it would be better for the region to cooperate in the financial sector without targeting asset prices and exchange rate stability.

\section{References}

Azis, Iwan J (2002). What Would Have Happened in Indonesia if Different Economic Policies had been Implemented When the Crisis Started? The Asian Economic Papers, vol. 1 no. 2, MIT Press

(forthcoming) IMF Perspectives and Alternative Views On the Asian Crisis: An Application of Analytic Hierarchy Process and Game Theory Approach in Partha Gangopadhyay and Manas Chatterji (eds), Globalization and Economic Reform, Edward Elgar.

and Walter Isard (1996), "The Use of the Analytic Hierarchy Process in Conflict Analysis and An Extension," Peace Economics, Peace Science and Public Policy, Vol 3, No 3.

and Wing Thye Woo (2003). "Establishing a Regional Financial Institution for East Asia to Support the Chiang-Mai Initiative." research report for the ADB-Institute, Tokyo.

Blustein, Paul. (2001). The Chastening. Public Affairs, New York.

Chaipravat, Olarn (2001), Towards a Regional Financing Arrangement in East Asia, paper presented at the ADBI/FIMA Symposium on "From the Asian Financial Crisis of 1997 to a Regional Financing Arrangement," Honolulu, Hawaii, May 10.

Eichengreen, Barry (2003). What to Do with the Chiang Mai Initiative, Asian Economic Papers, Vol 2, No. 1. MIT Press.

IMF, News Brief, No. 00/36, June 2, 2000

Mussa, Michael (2002). Reflection on Moral Hazards and Private Sector Involvement in the Resolution of Emerging Market Financial Crises, Institute for International Economics, Washington D.C.

Saaty, Thomas L (1996). Decision Making With Dependence and Feedback: The Analytic Network Process, RWS Publication, Pittsburgh.

Yoshitomi, Masaru and ADBI Staff (2003). Post-Crisis Development Paradigms in Asia, Asian Development Bank Institute (ADB-I), Tokyo.

Wang, Yunjong and Wing Thye Woo (2002). A Study on Information Exchange, Surveillance Systems, and Regional Institutions in East Asia, Asian Development Bank project on Monetary and Financial Cooperation in East Asia. 
Appendix 1. Main structure of top level network.

\begin{tabular}{|c|c|}
\hline $\begin{array}{l}\text { Alternative(s) } \\
\text { under it: }\end{array}$ & $\begin{array}{ll}\text { - } & \text { 1RFA-CommER } \\
\text { - } & \text { 2RFA-NoER } \\
\text { - } & \text { 3RFA-NoCommER }\end{array}$ \\
\hline Network Type: & Formulaic \\
\hline Formula: & 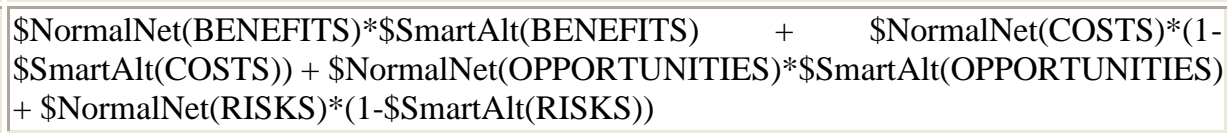 \\
\hline Clusters/Nodes & $\begin{array}{l}\text { - Goal Cluster: Cluster indentifying specifically the goal of the study, i.e., to } \\
\text { search for the most suitable RFA form. } \\
\text { Goal Node: RFA Search: Exploring alternative forms of Regional } \\
\text { Financial Arrangement (RFA) } \\
\text { - Objectives: asian countries objectives } \\
\circ \quad \text { Avoid Contagion: Avoid financial contagion in the region that could } \\
\text { destabilize even the relatively strong economy } \\
\circ \text { ER Stability: Minimize exchange rate instability. } \\
\circ \quad \text { Strengthening Financial Sector: Strengthen the region's financial } \\
\text { sector and develop the non-bank securities market } \\
\text { - Toplevel Model: This cluster contains Benefits, Costs, Risks and Opportunities } \\
\circ \text { BENEFITS: Benefits Merit of having a certain form of RFA } \\
\circ \text { COSTS: Costs Merit of having a certain form of RFA } \\
\circ \text { OPPORTUNITIES: Opportunities Merit arising from having a } \\
\circ \text { certain form of RFA } \\
\text { RISKS: Risks Merit of having a certain form of RFA }\end{array}$ \\
\hline
\end{tabular}




\section{Appendix 2. Main structure of BENEFITS network}

\begin{tabular}{|c|c|}
\hline $\begin{array}{l}\text { Alternative(s) in } \\
\text { it: }\end{array}$ & $\begin{array}{ll}\text { - } & \text { 1RFA-CommER } \\
\text { - } & \text { 2RFA-NoER } \\
\text { - } & \text { RFA-NoCommER }\end{array}$ \\
\hline Network Type: & Bottom level \\
\hline Formula: & Not applicable \\
\hline Clusters/Nodes & $\begin{array}{l}\text { 1BENEFIT CRITERIA: This cluster contains the benefits criteria } \\
\text { 1Regional-Focus: Focus on East Asian region, unlike the IMF's } \\
\text { golbal coverage } \\
\text { 2Voice: Raise the Asian voice and concerns in the international } \\
\text { financial fora } \\
\text { 3Quick Disbursement: Quick disbursement of liquidity support to } \\
\text { arrest the volatile movement of the ER } \\
\text { - 2FOCUS: The Focus of RFA } \\
\circ \text { 1Crisis Prevention: RFA focusing on crisis prevention } \\
\circ \text { 2Crisis Management: } R F A \text { focusing on crisis management } \\
\text { - 3ALTERNATIVES: This cluster contains the alternatives } \\
\circ \text { 1RFA-CommER: RFA with a common currency basket in order to } \\
\text { achieve ER stability } \\
\circ \text { 2RFA-NoER: Regional Financial Institution focusing on the } \\
\text { problems of weak banking system and undeveloped securities market } \\
\text { without specifying ER system and ER target } \\
\circ \text { 3RFA-NoCommER: RFA without a common currency basket but } \\
\text { aims at ER stability }\end{array}$ \\
\hline
\end{tabular}

Proceedings $-7^{\text {th }}$ ISAHP2003 Bali, Indonesia 


\section{Appendix 3. Main structure of COSTS network}

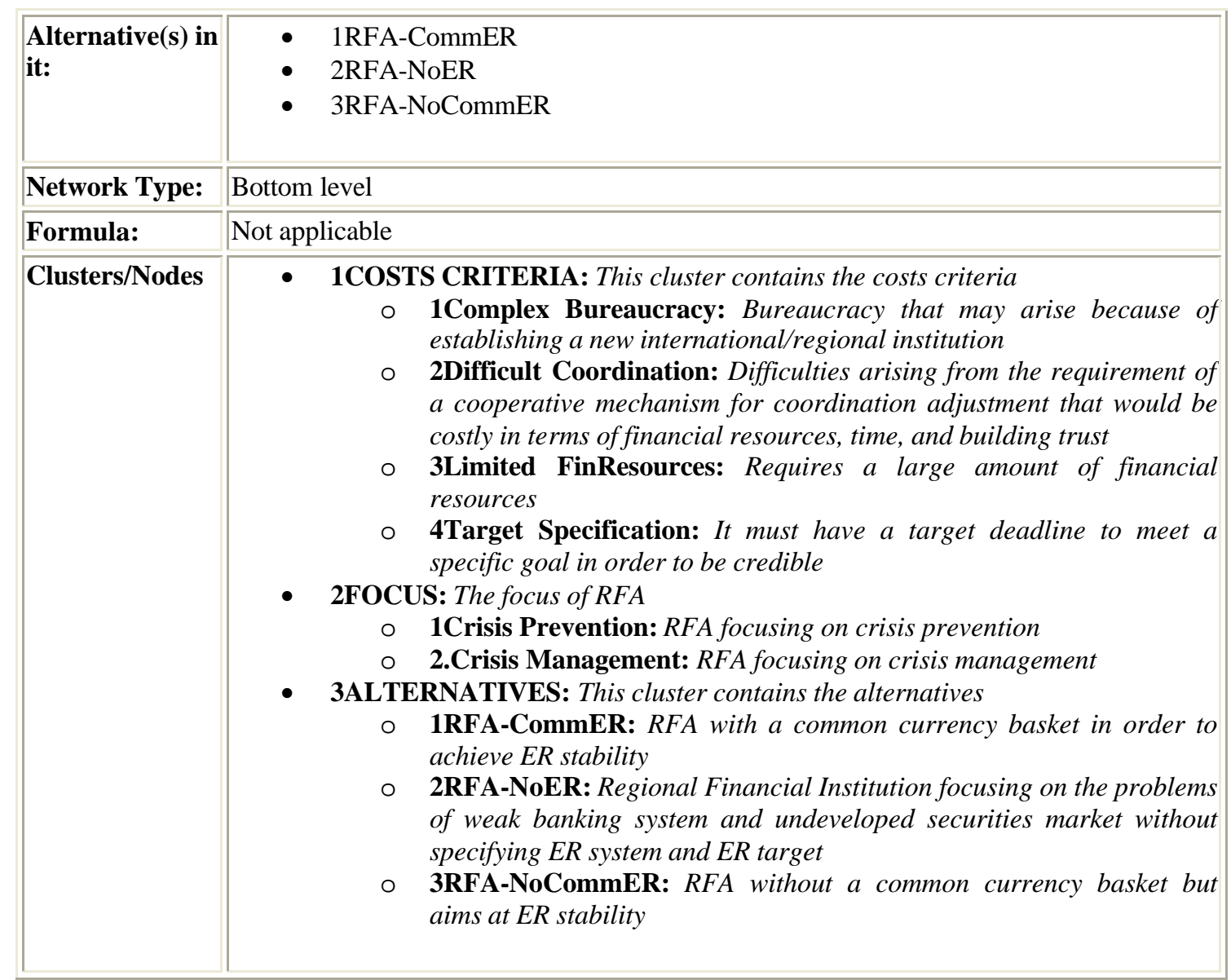




\section{Appendix 4. Main structure of OPPORTUNITIES network}

\begin{tabular}{|c|c|c|}
\hline $\begin{array}{l}\text { Alternative(s) } \\
\text { in it: }\end{array}$ & \multicolumn{2}{|c|}{$\begin{array}{ll}\text { - } & \text { 1RFA-CommER } \\
\text { - } & \text { 2RFA-NoER } \\
\text { - } & \text { 3RFA-NoCommER }\end{array}$} \\
\hline Network Type: & Bottom level & \\
\hline Formula: & Not applicable & \\
\hline Clusters/Nodes & $\begin{array}{r}\text { 10PPC } \\
\text { criteria } \\
\circ \\
\\
\circ \\
0 \\
\text { - 2FOCL } \\
\circ \\
\circ \\
\text { 3ALTF } \\
\circ \\
\circ \\
\end{array}$ & $\begin{array}{l}\text { RTUNITIES CRITERIA: This cluster contains the opportunities } \\
\text { 1Financial-Focus: Provide opportunities to the region to concentrate } \\
\text { on financial issues including the choices of policies which otherwise } \\
\text { unavailable under the IMF program (e.g., capital control, bail-in) } \\
\text { 2Foreign-Reserves: Providing opportunities in terms of alternative } \\
\text { use of foreign reserves which otherwise unproductive } \\
\text { 3Surveillance: An opportunity to have a more effective surveillance } \\
\text { and monitoring mechanisms that could be consistent with the } \\
\text { necessary conditionalities } \\
\text { JS: The focus of RFA } \\
\text { 1Crisis Prevention: RFA focusing on crisis prevention } \\
\text { 2Crisis Management: RFA focusing on crisis management } \\
\text { RNATIVES: This cluster contains the alternatives } \\
\text { 1RFA-CommER: RFA with a common currency basket in order to } \\
\text { achieve ER stability } \\
\text { 2RFA-NoER: Regional Financial Institution focusing on the problems } \\
\text { of weak banking system and undeveloped securities market, without } \\
\text { specifying ER system and ER target } \\
\text { 3RFA-NoCommER: RFA without a common currency basket but } \\
\text { aims at ER stability }\end{array}$ \\
\hline
\end{tabular}


Main structure of RISKS network

\begin{tabular}{|c|c|c|}
\hline $\begin{array}{l}\text { Alternative(s) } \\
\text { in it: }\end{array}$ & $\begin{array}{ll}\text { - } & 1 \mathrm{RFA}- \\
\text { - } & 2 \mathrm{RFA}- \\
\text { - } & 3 \mathrm{RFA}-\end{array}$ & $\begin{array}{l}\text { CommER } \\
\text { NoER } \\
\text { NoCommER }\end{array}$ \\
\hline Network Type: & \multicolumn{2}{|l|}{ Bottom level } \\
\hline Formula: & \multicolumn{2}{|l|}{ Not applicable } \\
\hline Clusters/Nodes & $\begin{array}{r}\text { 1RISK } \\
\circ \\
0 \\
\circ \\
\circ \\
\text { - } 2 \text { FOC } \\
\circ \\
\circ \\
\text { 3ALT } \\
\circ \\
\circ \\
\end{array}$ & $\begin{array}{l}\text { S CRITERIA: This cluster contains the risks criteria } \\
\text { 1DomCoordination: Risks of a conflict arising from the } \\
\text { incompatibility of RFA with the previous and existing arrangements, } \\
\text { e.g., with the IMF and other international organizations, and from a } \\
\text { low degree of financial technology and lack of expertise } \\
\text { 2Heterogeneity: Risks of a conflict and further suspicions due to } \\
\text { heterogeneity and disagreeable conditionalities } \\
\text { 3MoralHazard: Risks of creating a strong moral hazard, especially } \\
\text { when the conditionalities are too "soft" } \\
\text { 4Political: Risks associated with a lack of political integration. The } \\
\text { integration allows the creation of new institution with real power. } \\
\text { Absent of it could risk a failure of RFA } \\
\text { US: The focus of RFA } \\
\text { 1Crisis Prevention: RFA focusing on crisis prevention } \\
\text { 2Crisis Management: RFA focusing on crisis management } \\
\text { DNATIVES: This cluster contains the alternatives } \\
\text { 1RFA-CommER: RFA with a common currency basket in order to } \\
\text { acieve ER stability } \\
\text { 2RFA-NoER: Regional Financial Institution focusing on the problems } \\
\text { of weak banking system and undeveloped securities market withour } \\
\text { specifying ER system and ER target } \\
\text { 3RFA-NoCommER: RFA without a common currency basket but aims } \\
\text { at ER stability }\end{array}$ \\
\hline
\end{tabular}

